1 Lyman CA, Walsh TJ. Systemically administered antifungal agents. A review of their pharmacology and therapeutic applications. Drugs 1992;44:9-35.

2 Khoo SH, Bond J, Denning DW. Administering amphotericin B-a practical approach. J Antimicrob Chemother 1994;33:203-13.

3 Kirsh R, Goldstein R, Tarloff J, Parris D, Hook J, Hanna N, et al. An emulsion formulation of amphotericin B improves the therapeutic index when treating systemic murine candidiasis. J Infec Dis 1988;158:1065-70. when treating systemic murine candidiasis. J Infec Dis 1988;158:1065-70.
4 Joly V, Farinotti R, Saint-Julien L, Cheron M, Carbon C, Yeni P. In vitro renal toxicity and in vivo therapeutic efficacy in experimental murine cryptococcosis of amphotericin B (fungizone) associated with intralipid. Antimicrob Agents Chemother 1994;38:177-83.

5 Caillot D, Chavanet P, Casasnovas O, Solary E, Zanetta G, Buisson M, et al. Clinical evaluation of a new lipid-based delivery system for intravenous administration of Amphotericin B. Eur J Clin Microbiol Infect Dis 1992;11:722-5.

6 Caillot D, Casasnovas O, Solary E, Chavanet P, Bonnotte B, Reny G, et al. Efficacy and tolerance of an amphotericin B lipid (intralipid) emulsion in the treatment of candidaemia in neutropenic patients. J Antimicrob Chemother 1993;31:161-9.

7 Macedo MCMA, Dulley FL, Ostronoff M, Machado CM, Zambon E, Masumoto C, et al. Effectiveness of amphotericin B in lipid emulsion for treating fungal septicemia in granulocytopenic patients. Clin Infec Dis 1994;19:366-7.

8 Thakur CP. Comparison of glucose versus fat emulsion in the preparation of amphotericin B for use in kala-azar. Trans $R$ Soc Trop Med Hyg 1994;88:698-9.

9 Anderson RP, Clark DA. Amphotericin B toxicity reduced by administration in fat emulsion. Ann Pharmacother 1995;29:496-500.

10 Joly V, Geoffray C, Reynes J, Goujard C, Méchali D, Maslo C, et al. Amphotericin B in a lipid emulsion for the treatment of cryptococcal meningitis in AIDS patients. J Antimicrobiol Chemother 1996;38:117-26.

11 Villani P, Regazzi MB, Maserati R, Viale P, Alberici F, Giacchino R. Clini$\mathrm{cal}$ and pharmacokinetic evaluation of a new lipid-based delivery system of amphotericin B in AIDS patients. Arzneimittelforschung 1996;46:445-9.

12 Chavanet PY, Garry I, Charlier N, Caillot D, Kisterman JP, D’Athis M, et al. Trial of glucose versus fat emulsion in preparation of amphotericin for use in HIV infected patients with candidiasis. $B M J$ 1992:305:921-5.

13 Moreau P, Milpied N, Fayette N, Rameé JF, Harousseau JL. Reduced renal toxicity and improved clinical tolerance of amphotericin B mixed with intralipid compared with conventional amphotericin B in neutropenic patients. J Antimicrob Chemother 1992;30:535-41

14 Caillot D, Reny G, Solary E, Casasnovas O, Chavanet P, Bonnotte B, et al. A controlled trial of the tolerance of amphotericin $\mathrm{B}$ infused in dextrose or in intralipid in patients with haematological malignancies. J Antimicrob Chemother 1994;33:603-13.

15 Meyer P, Adam D, Hiddemann W, Link H, Maschmeyer G, Helmerking M. Interventionstherapie von Infektionen und Fieber unklarer Genese bei neutropenischen Patienten mit malignen hämatologischen Grunderkrankungen-Studie II. Zeitschrift für antimikrobielle antineoplastische Chemotherapie 1992;10:1-27.

16 Bodey G, Bueltmann B, Duguid W, Gibbs D, Hanak H, Hotchi M, et al. Fungal infections in cancer patients: an international autopsy survey. Eur Clin Microbiol Infec Dis 1992;11:99-109.

17 Schöffski P, Luttmann A, Petersen D, Schumann G, Rapp-Bernhardt U, Freund M. Amphotericin B-neue Darreichungsform eines bewährten Antimykotikums. Arzneimitteltherapie 1994;12:115-7.

18 Wright DG, Robichaud KJ, Pizzo PA, Deisseroth AB. Lethal pulmonary reactions associated with the combined use of amphotericin $\mathrm{B}$ and leukocyte transfusions. N Engl J Med 1981;304:1185-9.

19 Arning M, Heer-Sonderhoff AH, Wehmeier A, Schneider W. Pulmonary toxicity during infusion of liposomal amphotericin $\mathrm{B}$ in two patients with acute leukemia. Eur J Clin Microbiol Infec Dis 1995;14:41-3.

20 Lindholm M. The ability of critically ill patients to eliminate fat emulsions. J Drug Dev 1991;4(Suppl 3):40-2.

21 Sundström G, Zauner CW, Arborelius M. Decrease in pulmonary diffusion capacity during lipid infusion in healthy men. J Appl Physiol 1973;34:816-20.

22 Greene HL, Hazett D, Demaree R. Relationship between intralipidinduced hyperlipidemia and pulmonary function. Am J Clin Nutr 1976;29:127-35.

23 Belin RP, Bivins BA, Jona JZ, Young VL. Fat overload with a 10\% soybean oil solution. Arch Surg 1976;111:1391-9.

24 Wesson DE, Rich R, Zlotkin SH, Pencharz PB. Fat overload syndrome causing respiratory insufficiency. J Pediatr Surg 1984;19:777-8.

25 Heide PE, Hohenberger $\mathrm{H}$. Tensiometrische und konduktometrische Stabilitäts- untersuchungen von Amphotericin B in Fettemulsionen. Österreichische Krankenhaus Pharmazie 1996;10:36-43.

(Accepted 5 May 1998)

\title{
Perinatal death associated with planned home birth in Australia: population based study
}

\author{
Hilda Bastian, Marc J N C Keirse, Paul A L Lancaster
}

PO Box 569,

Blackwood SA

5051, Australia

Hilda Bastian,

consumer advocate

Department of

Obstetrics and

Gynaecology,

Flinders University

of South Australia,

Flinders Medical

Centre, GPO Box

2100, Adelaide SA

5100, Australia

Marc J N C Keirse,

professor

Australian Institute of Health and

Welfare, National

Perinatal Statistics

Unit, University of

New South Wales,

NSW 2052,

Australia

Paul A L Lancaster, associate professor

Correspondence to: Ms Bastian

hilda.bastian@

flinders.edu.au

BMJ 1998;317:384-8

\begin{abstract}
Objective: To assess the risk of perinatal death in planned home births in Australia.

Design: Comparison of data on planned home births during 1985-90, notified to Homebirth Australia, with national data on perinatal deaths and outcomes of home births internationally.

Results: 50 perinatal deaths occurred in 7002 planned home births in Australia during 1985-90: 7.1 per 1000 (95\% confidence interval 5.2 to 9.1$)$ according to Australian definitions and 6.4 per 1000 (4.6 to 8.3) according to World Health Organisation definitions. The perinatal death rate in infants weighing more than $2500 \mathrm{~g}$ was higher than the national average (5.7 versus 3.6 per 1000: relative risk $1.6 ; 1.1$ to 2.4 ) as were intrapartum deaths not due to malformations or immaturity ( 2.7 versus 0.9 per 1000 : $3.0 ; 1.9$ to 4.8$)$. More than half $(52 \%)$ of the deaths were associated with intrapartum asphyxia.

Conclusions: Australian home births carried a high death rate compared with both all Australian births and home births elsewhere. The two largest contributors to the excess mortality were underestimation of the risks associated with post-term birth, twin pregnancy and breech presentation, and a lack of response to fetal distress.
\end{abstract}

\section{Introduction}

Despite decades of political and academic debate the relative merits of home versus hospital birth remain unproved. This is likely to remain so. Comparisons that are sufficiently unbiased and large enough to address crucial safety issues are unlikely to be forthcoming. ${ }^{12}$ Although home and hospital offer different risks and benefits for births, neither has standard care characteristics. In fact the range from safe to unsafe practice may be wider within each location than it is between them. Addressing what constitutes safe birth practice at home may be a more pivotal concern than attempting to quantify the theoretical differences attributable to place of birth.

In the Netherlands, where $30 \%$ of births are planned to be at home, there is a widely accepted list of criteria for home birth. ${ }^{3}$ When home birth is uncommon, opinions and practice can vary more widely. Thus leaflets on informed choice of place of birth in the United Kingdom do not specify any contraindications to home birth. ${ }^{45}$ Others have advocated home birth for women at high risk of obstetric complications, ${ }^{67}$ and trends to abandon risk assessment for home birth are apparent in both Australia $^{8}$ and the United States. ${ }^{9}$ 
We evaluated the outcomes of Australian home births and compared these with all Australian births and planned home births elsewhere.

\section{Subjects and methods}

Data on planned home births

A planned home birth was defined as a birth that, at the onset of labour, was intended to occur at home with the assistance of a home birth practitioner. This definition excluded antepartum transfers, unplanned home births, and births where the woman was supported only by family and friends. Home birth practitioners included midwives and medical practitioners, both registered and non-registered, but not Aboriginal traditional midwives.

Data on home births during 1985-90 were from a database of Homebirth Australia, a national consumers' association that kept a register of practitioners attending home births. Practitioners were asked to complete a detailed notification form for each planned home birth. An annual summary of births attended was requested from practitioners who did not submit these forms.

All home birth practitioners, except one in 1988, supplied minimum data for births during 1985-8. For 1989 and 1990, $207(89.6 \%)$ practitioners provided data (24 non-participants). Information on 576 births attended by non-participants during 1989-90 was obtained from their notifications in home birth support group newsletters.

Overall, information was available for 7002 planned home births during 1985-90. Information came from individual notification forms in $5052(72 \%)$ births, from summaries in $1372(20 \%)$ births, and from home birth support group newsletters in $576(8 \%)$ births. Two additional births resulting in deaths were identified from other sources; these were confirmed by state perinatal data collections.

\section{Data on perinatal deaths}

Australian perinatal death refers to stillbirth and death within 28 days after birth, of an infant weighing $500 \mathrm{~g}$ or more. This definition includes stillbirths and deaths within the first week and late neonatal deaths.

An audit form was distributed to practitioners who had reported deaths during 1985-7 (20 deaths). All practitioners provided data. A similar request was made for the 11 deaths reported in 1988, but only five practitioners complied. For 1989 and 1990, practitioners reported nine deaths directly to Homebirth Australia; a further eight deaths were reported in newsletters in the states with non-participants. In addition, one home birth group notified a death that was matched in the state's perinatal data collection.

Data to supplement incomplete death reports during 1988-90 were sought from state perinatal data collections and registry data in one state. These sources provided additional data on four of the eight deaths identified only through newsletters during 1989-90, and on 13 deaths with minimum information during 1988-90. One state reported an additional death that met the study's criteria.

Overall, information was available on 50 deaths (five of which were late neonatal deaths) eligible for inclusion in this study. Eleven deaths reported to
Table 1 Causes of perinatal deaths in 7002 planned home births in Australia 1985-90

\begin{tabular}{lc} 
Cause & No of deaths \\
\hline Fetal deaths & \\
\hline Antepartum ${ }^{\star}$ & 3 \\
\hline Unexplained & 2 \\
\hline Severe fetal growth restriction & 1 \\
\hline Placental abruption & 4 \\
\hline Unknown antepartum or intrapartum & 14 \\
\hline Intrapartum: & 2 \\
\hline Intrapartum asphyxia & 2 \\
\hline Birth asphyxia due to shoulder dystocia & 1 \\
\hline Preterm twins & 1 \\
\hline Intrauterine infection (listeriosis) & 1 \\
\hline Tear of umbilical artery (in velamentaous insertion) & \\
\hline Unexplained & 7 \\
\hline Early neonatal deaths & 1 \\
\hline Intrapartum asphyxia & 1 \\
\hline Meconium aspiration & 3 \\
\hline Shoulder dystocia & 1 \\
\hline Lethal malformation & 1 \\
\hline Neonatal sepsis & 1 \\
\hline Unexplained & 1 \\
\hline Late neonatal deaths & 1 \\
\hline Intrapartum asphyxia & 1 \\
\hline Sudden infant death syndrome & \\
\hline Postviral cardiomyopathy & \\
\hline Chromosomal abnormality & \\
\hline Total & \\
\hline
\end{tabular}

*Antepartum deaths for which care was transferred to hospital before onset of labour not included.

Homebirth Australia did not meet our criteria and were excluded. Of the 50 deaths, 48 were notified by practitioners to Homebirth Australia or home birth newsletters and two came from other sources.

\section{Data analysis and comparisons}

Data on home births were compared with all Australian births during 1985-90 and with planned home births elsewhere, identified from a literature search for comparable data from the 1980s and 1990s. The cIA program was used for statistical analysis. ${ }^{10}$

\section{Results}

\section{Perinatal deaths}

Among the 7002 home births studied, there were 50 deaths (31 fetal and 19 neonatal) (table 1) giving a perinatal death rate of 7.1 per 1000 according to the Australian definition. Excluding the five late neonatal deaths gives a perinatal death rate of 6.4 per 1000 according to criteria of the World Health Organisation. Thirteen of the 31 stillbirths were born in hospital after transfer of the mother during labour, but at least 10 fetuses were dead on arrival in hospital. Three infants died during transfer to hospital, one before and two after birth. All but one of the 19 neonatal deaths occurred in infants born at home.

Although it is not known how often distance to hospital played a role in decisions on transfer, only once was distance cited as a prohibitive factor. Time in transit, when known, was less than 30 minutes for all deaths.

Of 43 deaths with known birthweight, 11 (25.6\%) were less than $2500 \mathrm{~g}$ of whom four were malformed. Of 44 deaths of known gestational age, eight (18.2\%) 
Table 2 Recognisable risk factors in pregnancies resulting in 23 deaths from intrapartum asphyxia*

\begin{tabular}{lcc} 
Variable & $\begin{array}{c}\text { Status known } \\
\text { No (\%) }\end{array}$ & $\begin{array}{c}\text { Data missing } \\
\text { No (\%) }\end{array}$ \\
\hline Meconium stained fluid & $13 / 15(86.7)$ & $8 / 23(34.8)$ \\
\hline Fetal bradycardia & $7 / 12(58.3)$ & $11 / 23(47.8)$ \\
\hline Breech presentation & $4 / 19(21.0)$ & $4 / 23(17.4)$ \\
\hline Intrauterine growth restriction & $4 / 20(20.0)$ & $3 / 23(13.0)$ \\
\hline Twin pregnancy & $2 / 23(8.7)$ & - \\
\hline Gestation: & & \\
\hline$\geqslant 42$ weeks & $6 / 21(28.6)$ & $2 / 23(8.7)$ \\
\hline$<37$ weeks & $1 / 21(4.8)$ & $2 / 23(8.7)$ \\
\hline
\end{tabular}

*Excludes three deaths due to shoulder dystocia, two of which had meconium stained fluid, but includes death due to meconium aspiration.

were preterm $(<37$ weeks $)$ and seven $(15.9 \%)$ post-term $(\geqslant 42$ weeks).

Twenty six deaths (52\%) were associated with intrapartum asphyxia, including three cases of shoulder dystocia and one case of meconium aspiration (table 1). The cause of death in eight cases $(16 \%)$ could not be explained owing to lack of data.

\section{Asphyxial deaths}

Three babies, weighing $4295 \mathrm{~g}, 4600 \mathrm{~g}$, and $6020 \mathrm{~g}$, died from non-anticipated shoulder dystocia; meconium had been noted during labour for two of them. Most other deaths from intrapartum asphyxia occurred in fetuses known to be at increased risk of perinatal asphyxia (table 2 ).

Table 3 Place of birth and death for 26 infants dying from intrapartum asphyxia, including shoulder dystocia and meconium aspiration

\begin{tabular}{lccccccc} 
& \multicolumn{2}{c}{ Place of birth } & & \multicolumn{4}{c}{ Place of death } \\
\cline { 2 - 3 } \cline { 6 - 8 } Time of death & Home & Hospital & & Home & Transit & Hospital & Unknown \\
\hline Intrapartum & 8 & 8 & & 13 & 1 & - & 2 \\
\hline Neonatal & 10 & - & & 2 & 1 & 7 & - \\
\hline
\end{tabular}

Table 4 Comparison of Australian perinatal mortality (includes stillbirth and early and late neonatal mortality) between planned home births and all Australian births, 1985-90

\begin{tabular}{|c|c|c|}
\hline & $\begin{array}{l}\text { Home births }(\mathrm{n}=7002) \\
(95 \% \mathrm{Cl})\end{array}$ & $\begin{array}{l}\text { All Australian births ( } \mathrm{n}=1502756) \\
\qquad(95 \% \mathrm{CI})\end{array}$ \\
\hline \multicolumn{3}{|l|}{ Deaths per 1000 total births: } \\
\hline Fetal deaths & $4.4(2.9$ to 6.0$)$ & 6.0 (5.9 to 6.2$)$ \\
\hline Neonatal deaths & 2.7 (1.5 to 3.9$)$ & 4.8 (4.7 to 4.9$)$ \\
\hline Fetal and neonatal deaths & $7.1(5.2$ to 9.1$)$ & 10.8 (10.6 to 10.9$)$ \\
\hline Birthweight specific mortality $\geqslant 2500 \mathrm{~g}^{\star}$ & 5.7 (3.5 to 7.9$)$ & $3.6(3.4$ to 3.6$)$ \\
\hline \multicolumn{3}{|l|}{ Intrapartum fetal deaths†: } \\
\hline Rate per 1000 births & 2.7 (1.5 to 3.9$)$ & $0.9(0.85$ to 0.95$)$ \\
\hline$\%$ of all deaths & 38.0 (24.7 to 52.8$)$ & $8.3(7.9$ to 8.8$)$ \\
\hline$\%$ of stillbirths & 61.3 (42.2 to 78.2$)$ & $14.9(14.2$ to 15.7$)$ \\
\hline
\end{tabular}

*Data for 1985-8 only.

†Excludes intrapartum deaths associated with congenital malformation or extreme immaturity, or both.

Table 5 International comparison of perinatal mortality (stillbirth and first week deaths according to WHO definitions) among planned home births starting labour at home

\begin{tabular}{|c|c|c|}
\hline Study & No of births & Deaths per 1000 births $(95 \% \mathrm{Cl})$ \\
\hline Present study, Australia 1985-90 & 7002 & $6.4(4.6$ to 8.3$)$ \\
\hline 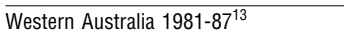 & 943 & $6.4(2.4 \text { to } 13.9)^{\star}$ \\
\hline New Zealand $1973-93^{14}$ & 9776 & $3.0(1.9$ to 4.0$)$ \\
\hline Wormerveer, Netherlands $1969-83^{15}$ & 6625 & $2.3(1.1$ to 3.4$)$ \\
\hline Gelderland, Netherlands $1990-93^{16}$ & 1140 & $3.5(0.9$ to 8.9$)$ \\
\hline United Kingdom $1994^{17}$ & 4665 & $1.1(0.1$ to 2.0$)$ \\
\hline Northern Health Region, UK 1981-94 ${ }^{18}$ & 1733 & 3.5 (1.3 to 7.5$)$ \\
\hline USA $1978-91^{19}$ & 11081 & $2.0(1.2$ to 2.9$)$ \\
\hline
\end{tabular}

${ }^{\star}$ These data also include late neonatal deaths.
Of those babies of known gestational age, seven $(33.3 \%)$ were outside term: one preterm and six post-term. Five asphyxial deaths were associated with malpresentation: four breech presentations diagnosed before labour and one face presentation. Two intrapartum asphyxial deaths occurred in second twins.

In most cases there had been warning signs during labour. Often these occurred early enough to have allowed timely transfer. In seven cases, meconium or bradycardia, or both, were noted several hours before fetal death. In some cases, risk factors and warning signs accumulated without prompting effective action. In none of the intrapartum asphyxial deaths was the fetus alive on arrival in hospital (table 3).

Two deaths occurred in water births $(\mathrm{n}=344)$; in both cases the fetal heart had not been listened to during second stage labour.

Comparison with Australian perinatal mortality During 1985-90 there were just over 1.5 million births in Australia, giving a death rate (including late neonatal deaths) of 10.8 per 1000 compared with 7.1 per 1000 in planned home births (table 4). In the home birth population, however, severe pathology and very preterm pregnancies with the highest risk of mortality are underrepresented. ${ }^{11}{ }^{12}$ For example in home births with known birthweight, only $1.4 \%$ were of low birthweight. ${ }^{11}{ }^{12}$ Birthweight specific mortality was calculated only for the years with the most comprehensive data (1985-8). The death rate for infants weighing $\geqslant 2500 \mathrm{~g}$ in $1985-8$ was 5.7 per 1000 in home births compared with 3.6 per 1000 nationally (relative risk $1.6 ; 95 \%$ confidence interval 1.1 to 2.4 ).

Intrapartum deaths mainly accounted for the high death rate in home births of babies weighing $\geqslant 2500 \mathrm{~g}$ (table 1). Intrapartum death not associated with congenital malformations or extreme immaturity (defined in the home birth group as an infant weighing $<1000 \mathrm{~g}$ ) was three times as frequent in planned home births than it was nationwide (3.0; 1.9 to 4.8 ) (table 4).

\section{Comparison with home birth internationally}

Comparison of data from reports on home births is hampered by large differences in definition and inclusion criteria. A search of the literature during the 1980 s and 1990s identified seven studies with definitions and criteria that permitted comparison with the national Australian data. These studies were from Australasia, ${ }^{13}{ }^{14}$ Europe,${ }^{15-18}$ and the United States. ${ }^{19}$ Australian planned home births had a perinatal death rate about twice as high as these countries (table 5).

Practitioners who continued participation in the study during 1989-90 had a perinatal death rate (3.8 per 1000) similar to that reported internationally, while the death rate for the remainder was estimated at 20.8 per 1000. This cannot be explained by under identification of births in the data for non-participants. Deaths may have been more fully ascertained than births, but home birth newsletters reported births for the non-participants with comparatively large caseloads, and the dataset shows no marked difference in the number of births per year. The number of missing births is therefore probably small. 


\section{Discussion}

Our analysis has shown cause for concern about some Australian home birth care. Firstly, the mortality is excessively high when considering that severe pregnancy disorders are grossly underrepresented in this population. ${ }^{112}$ The only category known to be overrepresented is post-term pregnancy $(10.7 \%)$. Secondly, in most countries the majority of deaths are preterm antepartum deaths and these are largely excluded by the definition of planned home birth. Thirdly, the intrapartum death rate among normally formed infants weighing $\geqslant 1000 \mathrm{~g}$ was three times higher than the national average. Fourthly, over half of all deaths were associated with intrapartum asphyxia. All these babies were born at home or if born in hospital were dead before arrival, while those referred after birth were all diagnosed with severe damage. Yet a large number were known to be at increased risk of intrapartum asphyxia before the onset of labour. Many of the deaths had been preceded by warning signs such as the presence of meconium and fetal bradycardia, in addition to pre-existing risks, without any action being taken or only too little, too late. The risk of death in such circumstances should not be underestimated, particularly as the capacity to care for severely asphyxiated babies at home is limited.

When compared with data on planned home birth in other industrialised countries, the perinatal death rate in Australia was much higher. There are several possible explanations for this. Firstly, our detection and ascertainment of deaths may have been better than it is elsewhere. Low participation in population based studies of planned home births is common. A national study from the United States for example achieved only a $67.6 \%$ response rate and surveyed registered midwives only. ${ }^{19}$

Secondly, Australian home birth practitioners might differ from home birth practitioners elsewhere. Home birth practice in Australia is nearly $100 \%$ private practice and characterised by low caseloads. On average during 1985-90, 53\% of practitioners attended less than five home births a year, and only $13 \%$ attended more than 20 home births a year. ${ }^{11}{ }^{12}$ This contrasts with the Netherlands, for instance, where home midwifery caseloads of more than 100 births a year are common. ${ }^{16}$ It is not known, however, if practitioners in our study also practised in other settings.

Thirdly, our study also included unregistered midwives. However, comparatively few births were attended by unregistered practitioners alone $(\mathrm{n}=737)$ and these births did not have a high death rate (2.7 per 1000).

A fourth, and more compelling explanation, is that some home birth practitioners in Australia no longer offer home birth to women at low risk. At least 18 deaths $(36 \%)$ in this study occurred in twins, post-term and preterm infants, and breech presentations, which would be contraindications for home birth elsewhere. Post-term births had a death rate twice that of other home births, and home birth mortality was 1 in 14 for breech presentation and 1 in 7 for twins. The two largest contributors to the excessive mortality were an underestimation of the risks of perinatal asphyxia in such births and, more generally, underestimation of the significance of fetal distress. This raises questions
- In some countries there is a trend towards high risk home births

- This study examined perinatal death rates in Australian home births, including both high and low risk births

- The death rate in Australian home births was higher than comparable births nationally and home births in other countries

- The higher perinatal death rate in Australian home births was due to the inclusion of predictably high risk births and prolonged asphyxia during labour

- While home birth for low risk women can compare favourably with hospital birth, high risk home birth is inadvisable and experimental

about other effects of prolonged asphyxia that were not addressed in this study.

We found only one other study, conducted in the United States, on mortality associated with breech, twin, and post-term births at home. ${ }^{9}$ This study showed excess mortality in such home births and voiced concern about the trend to encourage midwives to engage in high risk practice. We share that concern. Because of the well established risks and the lack of encouraging outcome data, such practice must be labelled as inadvisable and experimental with all ethical safeguards that pertain to clinical experimentation. Overintervention and lack of choice for women with high risk pregnancies, however, could well encourage some to choose home rather than hospital birth. In many Australian hospitals, women with breech presentation or twins, for example, would only be offered caesarean section.

Our study highlights the need for objective guidance on what constitutes safe practice for birth at home. Given the inadequacy of many national datasets, both in size and quality, such guidance must inevitably draw on international data to be valid and reliable. It may also require ongoing audit to detect patterns of avoidable problems. Australian women, like women elsewhere, will continue to choose to give birth at home. They and their infants are entitled to effective care and support in their choice.

We thank all practitioners who provided data and supported the study, and those who helped in the study design and implementation. We thank Ms Maggie Haertsch, Ms Dell Horey, the management committee of Homebirth Australia, and the committee convened to audit the perinatal deaths from 1985 to 1987 : Dr Heather Jeffrey (neonatologist), Dr Andrew Ramsay (home birth general practitioner), Ms Jan Robinson (home birth midwife), and the late Professor Rodney Shearman (obstetrician).

Contributors: $\mathrm{HB}$ designed the home birth data collection, liaised with Homebirth Australia and home birth practitioners, collected all home birth data, completed data entry, analysed data, participated in perinatal death audit, extracted birth and death data from home birth newsletters, sought additional data from perinatal data collections and death registry data, searched literature for comparable home birth studies, and cowrote the paper; she will act as guarantor for the paper. MJNCK reviewed all perinatal deaths, analysed perinatal death data, performed statistical analyses on study data and data from comparable home birth studies, and cowrote the paper. PALL participated in data analysis, designed and conducted perinatal death audit, 
sought additional data from perinatal data collections, performed comparative analyses of home birth and national perinatal death data, and contributed to the paper.

Funding: Data collection was funded by Homebirth Australia with some support from the Consumers' Health Forum of Australia. Review of perinatal deaths and home births 1988-90 was assisted by a grant from the National Health and Medical Research Council. The AIHW National Perinatal Statistics Unit is a collaborating unit of the Australian Institute of Health and Welfare. The views expressed in this article are those of the authors.

Conflict of interest: None.

1 Lumley J. Births at home: facts and fictions. Aust Fam Physician 1985;14:1104-7.

2 Macfarlane A. Trial would not answer key question, but data monitoring should be improved. BMJ 1996;312:754-5.

3 Ziekenfondsraad. Verloskundige indicatielijst 1987: final report of the working party to adjust the Kloostermanlist (WBK). Amstelveen: Ziekenfondsraad, 1987.

4 MIDIRS and the NHS centre for reviews and dissemination. Where will you have your baby-hospital or home? Informed choice for women. London: MIDIRS, 1997.

5 MIDIRS and the NHS centre for reviews and dissemination. Place of birth. Informed choice for professionals. London: MIDIRS, 1997.

6 Odent M. Homebirth for "high-risk" mothers. Mothering 1991;58:80-3.

7 Tew M. Safer childbirth? A critical history of maternity care, 2nd ed. London: Chapman and Hall, 1995:311-73.

8 Lecky-Thompson M. Questionable risk at home. In: Haertsch M, ed. Celebrating a revolution in birth:proceedings of the 10th national homebirth conference. Sydney: Homebirth Australia, 1989:43-58.
9 Mehl-Madrona L, Mehl-Madrona M. Physician- and midwife-attended home births: effects of breech, twin, and post-dates outcome data on mortality rates. Nurse Midwifery 1997;42:91-8.

10 Gardner MJ, Altman DG. Statistics with confidence. London: British Medical Journal, 1989.

11 Bastian H, Lancaster PAL. Home births in Australia 1988-1990. Sydney: AIHW National Perinatal Statistics Unit, 1992.

12 Bastian H, Lancaster PAL. Home births in Australia 1985-1987. Sydney: AIHW National Perinatal Statistics Unit, 1990.

13 Woodcock HC, Read AW, Moore DJ, Stanley FJ, Bower C. An epidemiological study of planned homebirths in Western Australia 1981-1987. Perth: Health Department of Western Australia.

14 Gulbransen G, Hilton J, McKay L, Cox A. Home birth in New Zealand 1973-93: incidence and mortality. NZ Med J 1997;110:87-9.

15 Van Alten D, Eskes M, Treffers PE. Midwifery in the Netherlands. The Wormerveer study; selection, mode of delivery, perinatal mortality and infant morbidity. BrJ Obstet Gynaecol 1989;96:656-62.

16 Wiegers TA, Keirse MJNC, van der Zee J, Berghs GA. Outcome of planned home and planned hospital births in low risk pregnancies: prospective study in midwifery practices in the Netherlands. BMJ 1996;313:1276-7.

17 Chamberlain G, Wraight A, Crowley P. Home births: the report of the 1994 confidential inquiry by the national birthday trust fund. Carnforth: Parthenon, 1996.

18 Northern Region Perinatal Mortality Survey Coordinating Group. Collaborative survey of perinatal loss in planned and unplanned home births. BMJ 1996;313:1306-9.

19 Anderson RE, Murphy PA. Outcomes of 11,788 planned home births attended by certified nurse-midwives: a retrospective descriptive study. Nurse Midwifery 1995;40:483-92.

(Accepted 5 May 1998)

\title{
Routine invitation of women aged 65-69 for breast cancer screening: results of first year of pilot study
}

\author{
Gary Rubin, Linda Garvican, Sue Moss
}

\section{See $p 376$ and Editorial by Werneke and McPherson \\ East Sussex Brighton and Hove Breast Screening Service, Royal Sussex County Hospital, Brighton BN2 5BE \\ Gary Rubin, director}

South East Institute of Public Health, Broomhill House, David Salomons' Estate, Tunbridge Wells, Kent

TN3 0XT

Linda Garvican, principal public health specialis

Cancer Screening Evaluation Unit, Institute of Cancer Research, Sutton, Surrey SM2 5NG

Sue Moss,

acting director

Correspondence to: Dr Garvican linda.garvican@

btinternet.com

BMJ 1998;317:388-9
Evidence from Sweden shows that screening for breast cancer is as effective in reducing mortality from the disease in women aged 65-69 as it is in women aged 50-64. ${ }^{1}$ However, although the British government's Forrest report recognised that older women were more likely to develop breast cancer, it recommended that they should not be routinely invited for screening because of low cost effectiveness from a likely low uptake and shorter life expectancy. ${ }^{2}$ Instead women over 64 years are entitled to self refer every three years-although few do so. ${ }^{3}$

A three-centre pilot study was established in which women aged 65-69 are routinely invited for breast screening. This study investigates the problems of extending the programme to this age group, and cost effectiveness. Based on the results a policy decision should be possible.

The East Sussex service started inviting women in May 1996, followed in 1997 by the Leeds and Wakefield, and Nottingham centres. We report on the uptake rate of women invited to attend for breast screening and the cancer detection rate in East Sussex during 1996-7.

\section{Subject, methods, and results}

Women aged 65-69 registered with general practitioners in East Sussex, Brighton, and Hove are invited for breast screening over a three year period. They attend two mobile screening units, which are also used for women aged 50-64. The pilot is integrated into the main breast screening programme, which is now in its third round.

The table summarises the results of the first year of the pilot. The results are computed in the same way as the annual statistics submitted to the Department of Health. Only 7.3\% (121/1655) of all invited women aged 68 or 69 had their last screen within 5 years; this is the proportion who volunteered for screening three years ago in the second round. Most $(59.0 \%, 976 / 1655)$ of the women aged 68 or 69 had their last screen over 5 years ago. They attended when last invited but were too old for a routine invitation three years ago. Of these women, $88 \%(858 / 976)$ attended when invited in the pilot study compared with $92 \%$ reattendance in women aged under 65 and 65-67 (10 954/11 945 and 1707/1859 respectively) who attended last time after routine invitations.

The overall uptake was $80 \%(16535 / 20810)$ for women under $65,76 \%(2386 / 3153)$ for those aged $65-67$, and $73 \%(1204 / 1655)$ for those aged 68 or 69. The total cancer detection rate in women under 65 was $7.1 / 1000(117 / 16535)$, higher than expected, rising to $8 / 1000(19 / 2386)$ in women aged $65-67$. In women aged 68 or 69 the rate was $17.4 / 1000(21 / 1204)$, reflecting both advancing age and that most had not been screened for six years.

\section{Comment}

These preliminary results show that those women who have previously attended for breast screening will continue to do so if invited after age 64, even if they have 